\title{
Playing by the rules? Phenotypic adaptation to temperate environments in an American marsupial
}

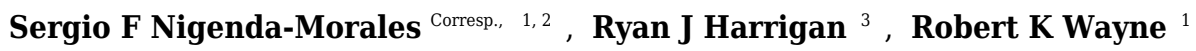 \\ 1 Department of Ecology and Evolutionary Biology, University of California, Los Angeles, Los Angeles, California, United States \\ 2 National Laboratory of Genomics for Biodiversity, Center for Research and Advanced Studies, Irapuato, Guanajuato, Mexico \\ 3 Center for Tropical Research, Institute of the Environment and Sustainability, University of California, Los Angeles, Los Angeles, California, United States \\ Corresponding Author: Sergio F Nigenda-Morales \\ Email address: snigenda@ucla.edu
}

Phenotypic variation along environmental gradients can provide evidence suggesting local adaptation has shaped observed morphological disparities. These differences, in traits such as body and extremity size, as well as skin and coat pigmentation, may affect the overall fitness of individuals in their environments. The Virginia opossum (Didelphis virginiana) is a marsupial that shows phenotypic variation across its range, one that has recently expanded into temperate environments. It is unknown, however, whether the variation observed in the species fits adaptive ecogeographic patterns, or if phenotypic change is associated with any environmental factors. Using phenotypic measurements of over 300 museum specimens of Virginia opossum, collected throughout its distribution range, we applied regression analysis to determine if phenotypes change along a latitudinal gradient. Then, using predictors from remote-sensing databases and a random forest algorithm, we tested environmental models to find the most important variables driving the phenotypic variation. We found that despite the recent expansion into temperate environments, the phenotypic variation in the Virginia opossum follows a latitudinal gradient fitting three adaptive ecogeographic patterns codified under Bergmann's, Allen's and Gloger's rules. Temperature seasonality was an important predictor of body size variation, with larger opossums occurring at high latitudes with more seasonal environments. Annual mean temperature predicted important variation in extremity size, with smaller extremities found in northern populations. Finally, we found that precipitation and temperature seasonality as well as low temperatures were strong environmental predictors of skin and coat pigmentation variation; darker opossums are distributed at low latitudes in warmer environments with higher precipitation seasonality. These results indicate that the adaptive mechanisms underlying the variation in body size, extremity size and pigmentation are related to the resource seasonality, heat conservation, and pathogen-resistance hypotheses, respectively. Our findings suggest that 
marsupials may be highly susceptible to environmental changes, and in the case of the Virginia opossum, the drastic phenotypic evolution in northern populations may have arisen rapidly, facilitating the colonization of seasonal and colder habitats of temperate North America. 
1 Playing by the rules? Phenotypic adaptation to temperate environments in an American

\section{2 marsupial}

3

4 Sergio F. Nigenda-Morales ${ }^{1,2}$, Ryan J. Harrigan ${ }^{3}$, Robert K. Wayne ${ }^{1}$

5

$6 \quad{ }^{1}$ Department of Ecology and Evolutionary Biology, University of California, Los Angeles, 610

7 Charles E Young Drive East, Los Angeles, CA, USA.

8

$9{ }^{2}$ National Laboratory of Genomics for Biodiversity, Center for Research and Advanced Studies,

10 Km. 9.6 Libramiento Norte Carretera León, Irapuato, Guanajuato, Mexico.

11

$12{ }^{3}$ Center for Tropical Research, Institute of the Environment and Sustainability, University of

13 California, 619 Charles E. Young Drive East, Los Angeles, CA, USA.

15 Corresponding author:

16 Sergio Nigenda-Morales

17 snigenda@ucla.edu 


\section{Abstract}

25 Phenotypic variation along environmental gradients can provide evidence suggesting local

26 adaptation has shaped observed morphological disparities. These differences, in traits such as

27 body and extremity size, as well as skin and coat pigmentation, may affect the overall fitness of

28 individuals in their environments. The Virginia opossum (Didelphis virginiana) is a marsupial

29 that shows phenotypic variation across its range, one that has recently expanded into temperate

30 environments. It is unknown, however, whether the variation observed in the species fits

31 adaptive ecogeographic patterns, or if phenotypic change is associated with any environmental

32 factors. Using phenotypic measurements of over 300 museum specimens of Virginia opossum,

33 collected throughout its distribution range, we applied regression analysis to determine if

34 phenotypes change along a latitudinal gradient. Then, using predictors from remote-sensing

35 databases and a random forest algorithm, we tested environmental models to find the most

36 important variables driving the phenotypic variation. We found that despite the recent expansion

37 into temperate environments, the phenotypic variation in the Virginia opossum follows a

38 latitudinal gradient fitting three adaptive ecogeographic patterns codified under Bergmann's,

39 Allen's and Gloger's rules. Temperature seasonality was an important predictor of body size

40 variation, with larger opossums occurring at high latitudes with more seasonal environments.

41 Annual mean temperature predicted important variation in extremity size, with smaller

42 extremities found in northern populations. Finally, we found that precipitation and temperature

43 seasonality as well as low temperatures were strong environmental predictors of skin and coat

44 pigmentation variation; darker opossums are distributed at low latitudes in warmer environments

45 with higher precipitation seasonality. These results indicate that the adaptive mechanisms

46 underlying the variation in body size, extremity size and pigmentation are related to the resource 
47 seasonality, heat conservation, and pathogen-resistance hypotheses, respectively. Our findings

suggest that marsupials may be highly susceptible to environmental changes, and in the case of the Virginia opossum, the drastic phenotypic evolution in northern populations may have arisen rapidly, facilitating the colonization of seasonal and colder habitats of temperate North America.

\section{Introduction}

Clinal geographic variation can arise as local adaptation within environmental gradients across the geographic range of a species, and can contribute to phenotypic divergence among populations (Mayr, 1956; Endler, 1977). Some of the most conspicuous traits capable of such responses to changes in the environment are body size, coloration, and body extremity dimensions, especially in species with large geographic ranges (Millien et al., 2006). These traits are functionally important, as they can affect numerous physiological and ecological processes in animals (Caro, 2005; Lomolino \& Perault, 2007; Tattersall et al., 2012). It is well-known that geographic variation of these traits between populations may follow general ecogeographic patterns; these include Bergmann's (larger body sizes in high, colder latitudes; Bergmann, 1847), Allen's (shorter extremities in higher latitudes; Allen, 1877) and Gloger's (less pigmentation in high latitudes; Gloger, 1833) rules. These patterns are thought to be the result of adaptations to selective pressures imposed by gradients in environmental variables (Mayr, 1956; Millien et al., 2006) and several hypotheses have been proposed to explain them. For example, thermoregulation, primary productivity and resource seasonality-fasting endurance have all been advanced as explanations for body size variation (Bergmann, 1847; Rosenzweig, 1968; Boyce, 1979; Lindstedt \& Boyce, 1985). Similarly, heat conservation may explain size change in extremities (Allen, 1877) and concealment, thermoregulation, prevention of cold injury and pathogen resistance may account for skin and coat pigmentation variation (Post, Daniels \& 
Binford, 1975; Mackintosh, 2001; Caro, 2005).

71 However, during or after a process of population expansion into new environments, the

72 ecogeographic patterns may not be observed, possibly because not enough time has elapsed for

73 adaptive changes to occur, or because trait plasticity may be more likely to drive phenotypic

74 differences during expansion (Ghalambor et al., 2007; Pfennig et al., 2010). Nevertheless, if

75 evidence for phenotypic adaptations is found, traits likely evolved quickly to match these new

76 environmental regimes (Hairston et al., 2005; Bradshaw \& Holzapfel, 2006). Finding the

77 environmental variables associated with geographic variation is important to elucidate the

78 evolutionary processes and mechanisms underlying phenotypic change (Kamilar et al., 2012).

79 The ecogeographic patterns mentioned above broadly apply to mammals (Ashton, Tracy \& de

80 Queiroz, 2000; Meiri \& Dayan, 2003), but limited studies have been done in marsupials (Yom-

81 Tov \& Nix, 1986; Lindenmayer et al., 1995; Quin, Smith \& Norton, 1996; Cooper, 1998), and to

82 our knowledge no studies have explored the effect of environmental variables on phenotypic

83 patterns in American marsupials. Marsupials represent the ancestor group of Eutherian

84 mammals; they have lower metabolism and body temperatures than Eutherians, probably making

85 them more susceptible to selective pressures related to environmental fluctuation (McNab, 1978;

86 Tyndale-Biscoe, 2005). The Virginia opossum (Didelphis virginiana Kerr 1792) is a nocturnal

87 marsupial widely distributed from northwestern Costa Rica to southern Ontario and British

88 Columbia in Canada. The species likely originated in tropical Central America (Gardner, 1973;

89 Jansa, Barker \& Voss, 2013), and the fossil record and paleoclimate data suggest it recently

90 expanded its range into the seasonal temperate habitats of North America, during the last $15-11$

91 kyr (thousand years) (Graham et al., 1996; Bartlein et al., 1998; Morgan, 2008; Graham \&

92 Lundelius, 2010). Although widely distributed, the Virginia opossum is mostly absent in xeric 
93 environments, and habitats with extremely low temperatures (Gardner \& Sunquist, 2003). This

94 species has poor thermoregulatory capabilities at low temperatures due to its high thermo-neutral

95 temperature (Lustick \& Lustick, 1972). However, individuals in northern populations develop a

96 higher fur density during the colder months (Gardner, 1973), which might be an adaptation to

97 low temperatures in seasonal habitats. These observations, combined with the tropical origin of

98 the species and its recent expansion into temperate climates, indicate the species is sensitive to

99 low temperatures and adaptations to these new environments may have evolved over a short

100 period of time.

101 The Virginia opossum shows phenotypic variation across its range for some body dimension and

102 coloration traits. Southern opossum populations have lower body weights and longer tails,

103 (although not necessarily shorter bodies) than those in northern localities (Gardner \& Sunquist,

104 2003). In addition, the proportion of the skin depigmented on the naked ears, feet, and tails is

105 greater in northern populations, which also have lighter pelage coloration of the face and the

106 dorsal part of the torso (Gardner, 1973; Gardner \& Sunquist, 2003). These phenotypic

107 characteristics may have been generated as a plastic response to the expansion into colder

108 climates or by rapid adaptive evolution in those environments. Previous research has only

109 generally described patterns of phenotypic variation across the distribution range of the Virginia

110 opossum, and had not considered associations with environmental variables (Gardner, 1973;

111 Koch, 1986; Gardner \& Sunquist, 2003). Consequently, the evolutionary processes driving the

112 extensive geographic variation in this species and other marsupials are poorly understood.

113 Due to its tropical origin, recent colonization of temperate regions, sensitivity to environmental

114 variables and phenotypic geographic variation, the Virginia opossum is a good model species to

115 study the evolutionary processes that have shaped phenotypic variation in marsupial mammals. 
116 Here we test if the phenotypic variation observed in the Virginia opossum follows ecogeographic

117 patterns and attempt to determine the adaptive mechanisms that may be driving this variation. If

118 no evidence of ecogeographic patterns are found, it would suggest population structure or plastic

119 responses may have played a greater role in driving the phenotype diversity in the species. We

120 implemented a machine learning algorithm to assess the association of geographic variation with

121 environmental variables and test different adaptive hypotheses. We used environmental

122 predictors corresponding to a wide range of habitat features, including temperature, precipitation,

123 elevation, moisture, and vegetation coverage, that have been suggested to affect coloration, body

124 and extremity size variation (Lindsay, 1987; Ashton, Tracy \& de Queiroz, 2000; Chaplin, 2004;

125 Caro, 2005; Kamilar et al., 2012; Terada, Tatsuzawa \& Takashi, 2012). We expect different sets

126 of environmental variables to be important predictors of geographic variation depending on the

127 adaptive hypotheses explaining this variation. For example, we predict that if thermoregulation is

128 the major adaptive explanation of body size variation in the Virginia opossum, it can be expected

129 that variables related to low temperatures to be the most important predictors for this trait. In

130 contrast, seasonality variables (for temperature or precipitation) would be more important if

131 resource availability is playing a larger role in the evolution of body size. In the case of extremity

132 size, we predict temperature or temperature changes would be important explaining extremity

133 size if heat-conservation strategies have played a role in the adaptation of opossums to temperate

134 environments. For skin and coat pigmentation traits, we would expect low temperature variables

135 to be important predictors if thermoregulation or cold injury are the selective mechanisms

136 underlying their variation. Conversely, if variables related to vegetation coverage are better

137 predictors of pigmentation, concealment probably has a more important adaptive role.

\section{Materials \& Methods}




\section{Museum specimens}

140 We examined 352 (163 females and 189 males) study skins of Virginia opossum museum

141 specimens to measure body and extremity dimensions, and 345 (159 females and 186 males)

142 specimens for skin pigmentation and coat coloration analysis (Table S1). The specimens belong

143 to five different natural history collections and were collected over 145 years (1865-2010; Table

144 S2) along the geographic range of the species, from southern Nicaragua to the northern east coast

145 of the United States (U.S.), including some specimens from the western US in California (Fig.

146 1). We obtained the coordinates for each specimen collecting locality using two different

147 approaches: 1) the coordinates provided by the original collectors; or 2) we located the collecting

148 site provided by the original collector using the Google Earth program and extracted the

149 geographic coordinates. Table S2, provides the geographic coordinates, year and country in

150 which the specimens were collected. To avoid the confounding effects of age, all specimens

151 measured for this study were adults. We determined the age following Gardner and Sunquist

152 (2003) age estimation method based on tooth eruption. For each specimen, we took

153 measurements to identify variation in body size, body extremities size, proportion of pigmented

154 skin of the extremities and, body and facial coat coloration. Twelve phenotypic traits were

155 measured in total, and because some specimens had damaged body parts, not all specimens were

156 measured for all traits (see Table S1). The variation in some of the traits is shown in Fig. 2.

157 UCLA's Office of Animal Research Oversight did not require a protocol or ethical approval for

158 this study since all analyses and measurements were carried out on museum specimens.

\section{Phenotypic measurements}

160 To quantify variation in body size, we measured body length (head and body; Fig. 2A) and left

161 hindfoot length (heel to tip of middle digit). Hindfoot size is often used as an alternative to 
162 represent body size because these traits frequently co-vary (Suttie \& Mitchell, 1983; Martin et

163 al., 2013). Consequently, since these measurements were positively correlated with each other $(r$

$164=0.547 ; P<0.001$ ), we used hindfoot length as an additional body size measurement in

165 subsequent analysis, instead of as a measurement of extremity size. For appendage size, we

166 measured the tail length (base to tip; Fig. 2B) and posterior aspect of the ear length (from base to

167 most superior part of the pinna). We measured the posterior aspect of the ear because most

168 specimens had their ears folded and it was impossible to measure the anterior part of the pinnae

169 (the more commonly used measurement). For simplicity, hereafter, we will refer to the posterior

170 aspect of ear length as ear length. All measurements were taken in centimeters to the nearest 0.1

171 decimal.

172 We measured four skin pigmentation traits by recording the proportion of the tail, ear, ventral 173 and dorsal aspect of the hindfoot's middle digit that was visibly pigmented (Fig. 2B, C). We

174 measured the proportion of pigmentation on both the ventral and dorsal part of the middle digit

175 because populations in the U.S. have hindfeet with light pigmentation on the sole and ventral

176 part of the toes, and in the most northern populations, the light pigmentation reaches the dorsal

177 part of the toes (Gardner, 1973).

178 Body and facial coat coloration measurements were taken using the tristimulus colorimeter

179 Minolta ChromaMeter CR-200 (Minolta, Osaka, Japan). This colorimeter measures the

180 reflectance of a xenon flash light and records the color in the three-dimensional color space

181 CIELab. The lightness axis $\left(L^{*}\right)$ expresses color brightness, with values ranging between 100

182 and 0 for white and black surfaces, respectively, whereas the $a^{*}$ and $b^{*}$ axes are the color

183 coordinates (Fullerton \& Keiding, 1997; Clarys et al., 2000). Since the phenotypes of coat

184 coloration in the Virginia opossum range from dark to light (Fig. 2A) we only used the 
185 information of the lightness axis $\left(L^{*}\right)$ in our analysis. The probe with the light source was held at

$18690^{\circ}$ angle to the surface parallel to the body axis, and the reflectance readings were recorded

187 manually. All reflectance measurements in each site were measured in triplicate and averaged to

188 calculate the total lightness value per site. We recorded reflectance values of lightness from three

189 facial traits (rostrum, cheek and temporal region) and from the torso of the body in nine sites (i.e.

190 three on the right flank, three on the dorsal stripe, and three on the left flank; see Fig. 3). The

191 mean of the torso measurements was used as the average torso lightness value.

\section{Environmental data}

193 For each locality where specimens were collected, we obtained information at 1-km spatial

194 resolution on 12 environmental variables, which have been reported to affect body and extremity

195 size, and pigmentation in mammal species (Lindsay, 1987; Ashton, Tracy \& de Queiroz, 2000;

196 Chaplin, 2004; Caro, 2005; Cordero \& Epps, 2012; Kamilar et al., 2012; Terada, Tatsuzawa \&

197 Takashi, 2012). Eight bioclimatic variables related to temperature (annual mean temperature,

198 mean temperature of warmest quarter, mean temperature of coldest quarter), precipitation

199 (annual precipitation, precipitation of coldest quarter), temperature seasonality (mean diurnal

200 range, temperature seasonality) and precipitation seasonality were obtained from the WorldClim

201 database (Hijmans et al., 2005; Table S3). These variables maximize variation in North America

202 while minimizing correlation (Harrigan et al., 2014). In addition, four variables were extracted

203 from remote-sensing databases: the maximum value of the normalized difference vegetation

204 index (NDVIMAX) that is related to vegetation density and productivity (Tucker \& Sellers,

205 1986; Buermann et al., 2008); the vegetation continuous field product as an estimate of the

206 percentage of tree coverage (TREECOV; Hansen et al., 2002); the monthly backscatter

207 measurements that capture attributes related to surface moisture (ROUGH) (Long et al., 2001); 
208 and elevation (ELEV) (Table S3). Elevation was included in the analyses due to its relationship

209 with temperature variation, which can influence the variance of several traits we examined

210 (Blackburn \& Ruggiero, 2001; Symonds \& Tattersall, 2010; Kamilar \& Bradley, 2011).

\section{Data analysis}

212 We carried out Shapiro-Wilk normality and Bartlett homoscedasticity tests for all the traits and

213 analyzed them accordingly. There is important sexual dimorphism in body and appendages size

214 in opossums (Gardner \& Sunquist, 2003); however, these measurements were normally

215 distributed and a preliminary analysis of our data showed that they have similar patterns of

216 latitudinal variation for males and females (Fig. S1 A-D). To insure adequate sample size for

217 body and extremity size measurements, we controlled for the effect of sex on these traits, and

218 used the residuals to analyze both sexes together. To test if there were differences in skin

219 pigmentation and coat coloration traits between males and females we used analysis of variance

220 (ANOVA) or Wilcoxon rank-sum test depending on the normality of the data. All traits had

221 homogeneity of variance, but only cheek and torso lightness were normally distributed and were

222 the only coloration traits statistically different between males and females (cheek lightness: $F=$

$22329.85, P<0.001$; coat lightness: $F=8.85, P=0.003)$, therefore we analyzed them separately for

224 both sexes. All tests were done using their standard functions in the R statistical framework

225 version 3.1.3 ( $\mathrm{R}$ core team, 2015).

226 Tests of correlation with latitude

227 To determine the relationship between the phenotypic traits and latitude, we carried out Pearson

$228(r)$ or Spearman $\left(r_{s}\right)$ correlation analyses depending on the normality of the data in the $\mathrm{R}$

229 statistical framework (R core team, 2015). Additionally, using the ggplot2 package in R

230 (Wickham, 2009), we plotted the trait values against latitude, implementing the non-linear 
231 regression loess function to graphically show the trend of correlations and the latitudes for which

232 there is a change in this trend.

\section{Association with environmental variables}

234 To detect if spatial autocorrelation was present in our phenotypic data, we calculated Moran's I

235 weighted by the Euclidean distance between two points for each trait using the ape package v.

2364.1 (Paradis, Claude \& Strimmer, 2004) in R. To identify the best environmental models for

237 predicting the phenotypic variation in the Virginia opossum, we ran random forest analyses using

238 the randomForest package v. 4.6-12 in R (Liaw \& Wiener, 2002; Prasad, Iverson \& Liaw, 2006).

239 Considering measurements from museum specimens that were collected in the same geographic

240 location could contribute to increase spatial autocorrelation in our data; therefore, we averaged

241 the phenotypic values of those specimens (Supplemental Dataset S1) for the random forest

242 analyses. To run the random forest analyses, we used the values of each phenotypic trait as

243 response variables, and the 12 environmental variables and two geographic variables (i.e. latitude

244 and longitude; Table S3) as predictors. The two geographic variables were included because

245 incorporating geographic information in random forest models allows an evaluation of how

246 much variation in response is explained by environmental variation as compared to simply

247 geographic proximity (Evans et al., 2011; Mascaro et al., 2014). Decision trees (regression or

248 classification) and random forest methods have no a priori assumptions about the relationship

249 between predictor and response variables, allowing for the possibility to analyze non-linear

250 relationships with complex interactions (Breiman, 2001, Cutler et al., 2007; Strobl, Malley \&

251 Tutz, 2009; Evans et al., 2011). Random forests analyses are iterations of large number of

252 decision trees, which recursively partition the data into binary homogeneous groups splitting the

253 response variable by the predictor variable explaining most of the remaining variance. The 
254 amount of variation in the response variable explained by each predictor is incorporated in the

255 model. Applying a randomized bootstrapping (bagging) method, random forest analysis uses a

256 subset of both response and predictor variables randomly permuted to construct each regression

257 tree and assess the robustness of the model based on the remaining data not included in the tree.

258 If the accuracy of the model decreases appreciably when a variable is left out of the model, that

259 variable is considered an important predictor of the data (Breiman, 2001; Prasad, Iverson \&

260 Liaw, 2006; Strobl, Malley \& Tutz, 2009).

261 We ran 10,000 regression trees for each random forest run, and after each run we eliminated the

262 least important variables in the model and re-ran random forest until we identified the most

263 predictive, least complex models, which were composed of three to five predictors that explained

264 the largest amount of variation for each trait. We compared these combined models (which

265 included environmental and geographic variables) with models composed only by the two

266 geographic variables and models including environmental variables only. This was done to

267 detect the role that geography or environment alone play in explaining phenotypic variation in

268 the opossum. Finally, we also tested for spatial autocorrelation in the residuals of the combined

269 models using the Moran's I statistic to be confident that spatial autocorrelation has not affected

270 the results of those models.

271 Results

\section{Latitudinal variation}

\section{Body and extremities size}

274 We found correlation with latitude for all body dimension measurements (see Table 1; Fig. 4A -

275 D). The correlations with latitude for body size and hindfoot length were positive $(r=0.314, P<$ 
2760.001 and $r=0.284, P<0.001$, respectively), increasing after $27^{\circ} \mathrm{N}$ (Fig. 4A, B). In contrast, the

277 correlations for tail length and ear length were negative (see Table 1). Tail length, was smaller

278 above $27^{\circ} \mathrm{N}$, whereas for ear length smaller values occur only in latitudes above $37^{\circ} \mathrm{N}$ (Fig. $4 \mathrm{C}$,

279 D). In general, opossums with smaller bodies but larger tails were distributed in latitudes below

$28027^{\circ} \mathrm{N}$, and larger individuals with shorter tails were found in higher latitudes. This pattern of

281 variation follows both Bergmann's and Allen's rule for body and extremity size, respectively.

\section{Skin and coat pigmentation}

283 There was negative correlation between all skin pigmentation traits and latitude (see Table 1;

284 Fig. 4E - H). The correlation was strong for tail pigmentation $\left(r_{s}=-0.701, P<0.0001\right)$ and

285 moderate for toe's ventral pigmentation $\left(r_{s}=-0.583, P<0.0001\right)$. The proportion of skin

286 pigmentation was lower above $26^{\circ} \mathrm{N}$ for all traits (Fig. 4E - H). For facial coat coloration traits,

287 lightness had a positive correlation with latitude (see Table 1), particularly noticeable for the

$288 \operatorname{rostrum}\left(r_{s}=0.679, P<0.0001\right)$ and temporal regions $\left(r_{s}=0.718, P<0.0001\right)$. These traits were

289 darkly or lightly pigmented below $25-26^{\circ} \mathrm{N}$ or above $30-31^{\circ} \mathrm{N}$, respectively, with a steep cline

290 between these latitudes (Fig. 4I, J). This is a common pattern we observed across many body

291 dimension and pigmentation traits where opossums below $27^{\circ} \mathrm{N}$ or above $31^{\circ} \mathrm{N}$ are

292 phenotypically similar among them (Fig. 4), suggesting that phenotypic variation is mainly

293 driven by individuals in the range between these latitudes probably due to environmental

294 conditions transitioning from tropical to temperate within this range. Finally, males were lighter

295 than females for cheek $(F=29.85, P<0.001)$ and torso coloration $(F=8.84, P=0.031)$. For

296 both sexes, cheek lightness had larger values above $24^{\circ} \mathrm{N}$ (Fig. 4K). Weak but significant

297 correlation with latitude was found for torso lightness in both sexes (Table 1), with lightness

298 increasing around $29^{\circ} \mathrm{N}$ (Fig. 4L). Overall, our skin and coat pigmentation data follow Gloger's 
299 rule: opossums have higher proportion of their skin pigmented and darker fur coloration on their

300 face and torso in lower latitudes, whereas less pigmented individuals with lighter face and torso

301 are found at higher latitudes.

\section{Association with environmental variation}

303 Concordant with our results of latitudinal variation, we found that all phenotypic traits show 304 positive spatial autocorrelation (Table S4) and the most important variable for the models of

305 these traits was latitude, whereas longitude was not consistently among the top variables (Fig. 5).

306 Despite this association between morphology and latitude, environment also helped predict

307 morphological characteristics; models with environmental or geographic variables alone

308 explained less of the Virginia opossum phenotypic variation than the combined models including

309 environmental and geographic variables together (Table 2). Further, the residuals of these

310 combined models showed small negative Moran's I values, most of them were slightly

311 significant or not significant (Table S5), which indicates the models are appropriate for our

312 analyses since they control for spatial autocorrelation. As such, we explore and explain these

313 more predictive, combined models below.

\section{Body and extremity size}

315 Combined models explained $12.75 \%$ and $14.95 \%$ of the total variation in hindfoot and body

316 length, respectively, and $47.42 \%$ of tail length variation (Table 2). Aside from latitude, the most

317 important environmental predictors for both body size and hindfoot length were temperature of

318 the coldest quarter (Bio11) and temperature seasonality (Bio4; Table 2; Fig. 5A, B), (Wigginton

$319 \&$ Dobson, 1999). The temperature of the coldest quarter (Bio11) was also the most important

320 environmental predictor of tail length (Table 2; Fig. 5C), whereas $13.11 \%$ of the ear length

321 variance was explained by the model [and its main environmental predictor, annual mean 
322 temperature (Bio1)] (Table 2; Fig. 5D). Together, the distribution of the opossums and the

323 combined models indicate that larger opossums occur (above $\left.27^{\circ} \mathrm{N}\right)$ where there is higher

324 temperature seasonality (Fig. 6A). Whereas for the extremity size variation, tail length was

325 reduced above $27^{\circ} \mathrm{N}$, in regions where the mean temperature during the winter (i.e. the coldest

326 quarter) is relatively low (Fig. 6B).

327 Skin and coat pigmentation

328 Combined models explained $31.17-62.56 \%$ of the variation in skin pigmentation, $13.75-$

$32978.34 \%$ in face coloration, and $14.41-19.88 \%$ in torso coloration (Table 2). The most

330 important and consistent environmental predictors for explaining phenotypic variation in skin

331 pigmentation and face coloration traits were temperature seasonality, temperature of coldest

332 quarter, along with two precipitation variables: precipitation seasonality (Bio15) and

333 precipitation of the coldest quarter (Bio19; Table 2; Fig. 5E - L). According to the distribution of

334 these predictors and of the opossums, individuals with more depigmented skin and lighter face

335 (distributed above $27^{\circ} \mathrm{N}$ ) were found in localities where temperatures during the coldest quarter

336 (i.e. winter; Fig. 6B) and precipitation seasonality are low (Fig. 6C), while temperature

337 seasonality (Fig. 6A) and precipitation of the coldest quarter are higher (Fig. 6D).

338 In contrast with other pigmentation traits, the combined models explained relatively less of the

339 variation in torso lightness, for males (14.41\%) and females (19.88\%), with temperature

340 seasonality, temperature of the coldest quarter and annual precipitation (Bio12) being the most

341 important environmental predictors (Table 2; Fig. 5M, N). A pattern of lighter torso coloration

342 was found where temperature seasonality was higher and temperature of the coldest quarter and

343 annual precipitation were lower. These results together with our latitudinal distribution results

344 suggest opossums have high proportion of skin pigmented and darker pelage on the face and 
345 torso in humid tropical environments below $26^{\circ} \mathrm{N}$, where conditions are warmer, less seasonal

346 and with higher precipitation variability, whereas they are less pigmented towards seasonal, drier

347 and colder habitats above $31^{\circ} \mathrm{N}$.

\section{Discussion}

\section{Adaptation to temperate and seasonal environments}

350 Our results indicate that there is a dramatic phenotypic change between tropical and temperate

351 Virginia opossum populations. This change may be driven by natural selection since they adjust

352 to three ecogeographic patterns. The facts that the traits show spatial autocorrelation (Table S4)

353 and that latitude was the most important variable for most of the models (Fig. 5) is not

354 surprising, given the latitudinal gradient we observed in the pattern of phenotypic variation

355 (Table 1) and that environmental variables are also correlated with latitude. Therefore, it is

356 difficult to distinguish the effects of pure spatial autocorrelation when environmental variables

357 that change along similar gradients, which is a limitation of studies perform at large spatial

358 scales. However, the inclusion of latitude and longitude as predictor variables allows us to better

359 tease apart the contributions of geography and ecology separately in our random forest models

360 (Evans et al., 2011; Mascaro et al., 2014) and control for spatial autocorrelation (Table S5). The

361 results of these models support the idea that phenotypic variation in the opossum follow

362 ecogeographic patterns that vary with latitude and identify the most important environmental

363 variables responsible for those patterns.

364 Koch (1986) detected a similar trend as we observed, that of increasing body size with latitude

365 using the lower first molar area as body size surrogate, but the association to environmental

366 variables was not tested in that study. The association we found of larger hindfoot and body size 
367 with environmental predictors of seasonality (Table 2; Fig. 5A, B), is consistent with the

368 resource seasonality (also known as fasting endurance) hypothesis as an explanation for

369 Bergmann's rule. This hypothesis suggests natural selection favors larger individuals in regions

370 of greater seasonality where food availability and energy demands are less predictable (Boyce,

371 1979; Lindstedt \& Boyce, 1985). For the opossum, one of the most important causes of mortality

372 is starvation due to harsh climate conditions in the winter, especially in the northern part of its

373 distribution (Kanda \& Fuller, 2004; Kanda, 2005). The main factors predicting whether an

374 opossum will survive the winter are body weight and size (Brocke, 1970; Kanda, 2005). Larger

375 individuals save more energy than smaller ones, owing to a lower metabolism at low

376 temperatures $(\mathrm{McNab}, 1978)$. Moreover, the seasonality hypothesis predicts that larger

377 individuals accumulate more fat and metabolize it at lower rates than smaller ones, having

378 greater fasting endurance and survival probability (Lindstedt \& Boyce, 1985; Millar \& Hickling,

379 1990). In accordance, under fasting conditions, opossums change from using carbohydrates as

380 energy source to lipid storage (Weber \& O'Connor, 2000). Our data suggests that the selective

381 pressure of weather-driven food seasonality and availability may have resulted in a phenotypic

382 adaptation of the Virginia opossum towards larger bodies in seasonal and temperate

383 environments above $27^{\circ} \mathrm{N}$. This finding is supported by the fact that at least some Australian

384 marsupials conform with Bergmann's pattern in response to temperature variability and food

385 availability (Yom-Tov \& Nix, 1986; Quin, Smith \& Norton, 1996).

386 The variation of body extremities, especially for tail length, follow Allen's rule (Fig. 4C, D) and

387 is associated with temperature variables (Table 2; Fig. 5C, D). Allen's pattern suggests that

388 natural selection favors individuals with larger body appendages that increase surface area to

389 dissipate heat via conduction in warmer climates, whereas in colder climates shorter appendages 
390 would be favored to reduce heat loss (Millien et al., 2006; Tattersall et al., 2012). This pattern is

391 found in two kangaroo species (Yom-Tov \& Nix, 1986) while other three Australian marsupials

392 do not show this pattern (Yom-Tov \& Nix, 1986; Lindenmayer et al., 1995; Cooper, 1998).

393 Physiological studies have proposed the Virginia opossum is poorly adapted to cold climates due

394 to its high conductivity (i.e. its skin facilitates heat transfer) and low metabolism, and because it

395 relies on behavioral and heat production mechanisms instead of heat conservation as a primary

396 thermoregulatory strategy (Lustick \& Lustick, 1972; Hsu, Harder \& Lustick, 1988). However,

397 opossums at high latitudes show heat conservation adaptations to seasonal decrease in

398 temperature by developing a higher pelage density during fall and winter months (Gardner,

399 1973). All physiological studies in this species have used individuals from northern populations

400 above $29^{\circ} \mathrm{N}$ [i.e. Florida (McNab, 1978), Ohio (Lustick \& Lustick, 1972; Hsu, Harder \& Lustick,

401 1988), Michigan (Brocke, 1970) and New York (McManus, 1969)], which our results revealed

402 are phenotypically more similar among them than compared with southern populations.

403 Consequently, further research is needed to explore the physiological characteristics of tropical

404 populations. As we have shown, northern populations may have phenotypic adaptations to colder

405 climates favoring heat conservation compared to populations in the south. It is possible that

406 during the northwards expansion of the species the new selective pressures imposed by colder

407 environments favored individuals with reduced extremities that conserved heat better.

408 Finally, the conformance to Gloger's pattern of skin and coat pigmentation variation and its

409 association with temperature and precipitation variables (Table 2; Fig. 5E - N) may be driven by

410 pathogens. The pathogen-resistant hypothesis suggests the higher pathogenic incidence in humid

411 and warm tropical environments (Guernier, Hochberg \& Guégan, 2004; Lafferty, 2009) is the

412 selective pressure driving the increased pigmentation observed in tropical populations, because 
413 highly pigmented skin, hair or feathers confer better resistance to pathogenic infection

414 (Mackintosh, 2001; Burtt \& Ichida, 2004). Accumulating evidence suggests that melanocytes,

415 melanosomes and melanin function as integral part of the innate immune system response

416 against invading pathogens (Mackintosh, 2001; Elias, 2007). For example, darker humans are

417 less prone to bacterial and fungal infections than individuals with light skin (Mackintosh, 2001),

418 black feathers on birds are more resistant to bacterial degradation than light ones (Burtt \& Ichida,

419 2004), and darker greenfinches (Carduelis chloris) have higher survival to protozoan infections

420 than paler ones (Männiste \& Hõrak, 2014). Similar to the other phenotypic traits we analyzed,

421 the evolution of adaptations in pigmentation (in the opossum's case is depigmentation) must

422 have occurred during the expansion of the species into North America's drier and temperate

423 environments at the end of the last Ice Age.

424 Taken together, our results suggest that the strong geographic variation observed in body size,

425 extremity size and pigmentation traits in the Virginia opossum represent phenotypic adaptations

426 of a species of tropical origins to more seasonal, colder and drier environments. These

427 adaptations may have arisen rapidly, around 15 - $11 \mathrm{ka}$ (thousand years ago), during the initial

428 phase of the range expansion of the species (Graham et al., 1996; Morgan, 2008; Graham \&

429 Lundelius, 2010), which may have facilitated the survival of individuals and the colonization of

430 temperate North America. This is a feasible scenario since rapid adaptation to environmental

431 changes can be accomplished within a few generations (Berteaux et al., 2004; Hairston et al.,

432 2005; Bradshaw \& Holzapfel, 2006).

\section{Coloration differences in sexes}

434 As torso and cheek coloration were the coat coloration traits with less variation explained by the

435 environmental variables that we analyzed (Table 2), it is possible there are other factors we did 
436 not consider in our analysis, for example, predation, sexual selection or communication, that

437 could also be important for explaining their variation. The fact that, for these two traits alone,

438 females were darker than males, suggest sexual selection may be playing a role, and requires

439 further investigation.

440 Phenotypic plasticity

441 There is the possibility that some of the patterns we observed might be achieved via phenotypic

442 plasticity (Ghalambor et al., 2007; Pfennig et al., 2010). In a marsupial species (Sminthopsis

443 crassicaudata), the difference in body size was found to be a response to temperature changes

444 (Riek \& Geiser, 2012). Our results for body size variation detected low temperatures as an

445 important predictor, making this alternative hypothesis plausible, however, experimental studies

446 should be done to further investigate the role of plasticity in opossum body size variation.

447 Experimental studies in several mammal species (Ashoub, 1958; Lee, Chu \& Chan, 1969;

448 Weaver \& Ingram, 1969; Serrat, 2013) have shown that body extremity size of genetically

449 similar individuals (i.e. siblings) varies depending on the temperature at which they are reared,

450 resulting in larger and shorter extremities in warm and cold conditions, respectively. However,

451 the only similar experiment done in a marsupial species did not find differences in extremity size

452 (Riek \& Geiser, 2012). Finally, Siamese cats (Iljin \& Iljin, 1930) among other mammals

453 (Robinson, 1973) show acrosematic pigmentation, with darker pigmentation on the ears, feet, tail

454 and face, whereas the rest of the body is lighter. This pattern is due to temperature differences in

455 the skin of the appendages and face compared to the core of the body, in which the appendages

456 are the coolest (Stern, 1968). Nevertheless, the pigmentation pattern in the Virginia opossum is

457 the opposite of that predicted by acrosematic patterns. The role of plasticity in the Virginia

458 opossum phenotype variation should be further explored, common garden studies rearing 
459 individuals with distinct phenotypes in different environmental conditions and obtaining

460 backcrossed generations may allow to assess the heritability of the traits.

461 Conclusions

462 Due to the lower body temperature and metabolism that marsupials have, compared to Eutherian

463 mammals, they may be more susceptible to the effects of environmental variables and would be

464 under high selective pressure to adaptively respond to environmental changes. For the Virginia

465 opossum, this prediction appears to be true. We have shown that temperature and precipitation

466 variables are important in shaping the geographic variation of body size, extremity size, and skin

467 and coat coloration in this species. Our results contribute to a better understanding of the

468 evolution of phenotypic traits in marsupials and provide evidence that selective pressures from

469 environmental variables influence greatly their phenotypic variation. In the Virginia opossum,

470 variation conforms to three main ecogeographic patterns. The phenotypic divergence observed

471 may have occurred relatively recently, during the last $15 \mathrm{kyr}$ the species has inhabited temperate

472 environments of North America, which shows the ability of this species for expanding in range

473 and rapidly adapting to new conditions. Although we cannot rule out the possibility that adaptive

474 phenotypic plasticity has played some role in driving these phenotypic patterns, our results better

475 support an adaptive response through the recent action of natural selection. Further research on

476 developmental physiology, population structure, demographic history and gene expression would

477 be needed to further test ideas about phenotypic variation in this marsupial species.

478 Acknowledgments

479 The authors would like to thank Nicole Corpuz and Adriana Garmendia for their help capturing

480 the phenotypic data. We are thankful with Alfred Gardner and Suzzane Peurach (USNM), Eileen 
481 Westwig (AMNH), Chris Conroy (MVZ, University of California, Berkeley), Livia Leon-

482 Paniagua (Museo de Zoología, Facultad de Ciencias, UNAM), Fernando Cervantes and Yolanda

483 Hortelano (CNM, Instituo de Biología, UNAM) for granting us access to their respective

484 museum collections.

485 References

486 Allen JA. 1877. The influence of physical conditions in the genesis of species. Radical Review

$487 \quad \mathbf{1}: 108-140$.

488 Ashoub MA. 1958. Effect of two extreme temperatures on growth and tail-length of mice.

$489 \quad$ Nature 181:284.

490 Ashton KG, Tracy MC, de Queiroz A. 2000. Is Bergmann's rule valid for mammals? American

$491 \quad$ Naturalist 156:390-415.

492 Bartlein PJ, Anderson KH, Anderson PM, Edwards ME, Mock CJ, Thompson RS, Webb RS,

493 Webb III T, Whitlock C. 1998. Paleoclimate simulations for North America over the past

49421,000 years: features of the simulated climate and comparisons with paleoenvironmental 495 data. Quaternary Science Review 17:549-585.

496 Bergmann C. 1847. Über die Verhältnisse der wärmeokönomie der Thiere zu ihrer Grösse.

$497 \quad$ Göttinger Studien 3:595-708.

498 Berteaux D, Réale D, McAdam AG, Boutin S. 2004. Keeping pace with fast climate change: can

499 artic life count on evolution? Integrative and Comparative Biology 44:140-151.

500 Blackburn TM, Ruggiero A. 2001. Latitude, elevation and body mass variation in Andean

501 passerine birds. Global Ecology and Biogeography 10:245-259.

502 Boyce MS. 1979. Seasonality and patterns of natural selection for life histories. American

$503 \quad$ Naturalist 114:569-583. 
504 Bradshaw WE, Holzapfel CM. 2006. Evolutionary response to rapid climate change. Science

505

506

507

508

509

510

511

512

513

514

515

516

517

518

519

520

521

522

523

524

525

526 312:1477-1478.

Breiman L. 2001. Statistical modeling: The two cultures (with comments and a rejoinder by the author). Statistical Science 16:199-231.

Brocke RH. 1970. The winter ecology and bioenergetics of the opossum, Didelphis marsupialis, as distributional factors in Michigan. PhD Thesis, Michigan State University.

Buermann W, Saatchi S, Smith TB, Zutta BR, Chaves JA, Milá B, Graham CH. 2008. Predicting species distributions across the Amazonian and Andean regions using remote sensing data. Journal of Biogeography 35:1160-1176.

Burtt EH, Ichida JM. 2004. Gloger's rule, feather-degrading bacteria, and color variation among song sparrows. Condor 106:681-686.

Caro T. 2005. The adaptive significance of coloration in mammals. Bioscience 55:125-136.

Chaplin G. 2004. Geographic distribution of environmental factors influencing human skin coloration. American Journal of Physical Anthropology 125:292-302.

Clarys P, Alewaeters K, Lambrecht R, Barel AO. 2000. Skin color measurements: comparison between three instruments: the chromameter, the dermaspectrometer and the mexameter. Skin Research and Technology 6:230-238.

Cooper ML. 1998. Geographic variation in size and shape in the southern brown bandicoot, Isoodon obesulus (Peramelidae: Marsupialia), in western Australia. Australian Journal of Zoology 46:145-152.

Cordero GA, Epps CW. 2012. From desert to rainforest: phenotypic variation in functionally important traits of bushy-tailed woodrats (Neotoma cinerea) across two climatic extremes. Journal of Mammalian Evolution 19:135-153. 
527 Cuarón AD, Emmons L, Helgen K, Reid F, Lew D, Patterson B, Delgado C, Solari S. 2008.

528 Didelphis virginiana. The IUCN Red List of Threatened Species, version 2015.1. Available

529 at: http://dx.doi.org/10.2305/IUCN.UK.2008.RLTS.T40502A10319531.en (accessed 4

$530 \quad$ December 2015).

531 Cutler DR, Edwards TC Jr, Beard KH, Cutler A, Hess KT, Gibson J, Lawler J. 2007. Random

532 forests for classification in ecology. Ecology 88:2783-2792.

533 Elias, PM. 2007. The skin barrier as an innate immune element. Seminars in Immunopathology

$534 \quad 29: 3-14$

535 Endler JA. 1977. Geographic variation, speciation, and clines. Princeton: Princeton University $536 \quad$ Press.

537 Evans JS, Murphy MA, Holden ZA, Cushman S. 2011. Modeling species distribution and change 538 using random forest. In: Drew CA, Wiersma Y, Huettmann F, eds. Predictive species and habitat modeling in landscape ecology. New York: Springer, 139-159.

540

541

542

543

544

545

546

547

548
Fullerton A, Keiding J. 1997. A comparison between a tristimulus colorimeter (Minolta ChromaMeter CR-200) and two spectrophotometers (Minolta Spectrophotometer CM-508i and CM-2002). Quantification of UV-B induced erythema in a hairless guinea pig. Skin Research and Technology 3:237-241.

Gardner AL. 1973. The systematics of the genus Didelphis (Marsupialia: Didelphidae) in North and Middle America. Special Publications Museum Texas Tech University 4:1-81.

Gardner AL, Sunquist ME. 2003. Opossum, Didelphis virginiana. In: Feldhamer GA, Thompson BC, Chapman JA, eds. Wild mammals of north America. Baltimore: Johns Hopkins University Press, 3-29. 
549 Ghalambor CK, McKay JK, Carroll SP, Reznick DN. 2007. Adaptive versus non-adaptive

550 phenotypic plasticity and the potential for contemporary adaptation in new environments.

551 Functional Ecology 21:394-407.

552 Gloger CL. 1833. Das Abändern der vögel durch einfluss des klimas. Breslau: August Schulz.

553 Graham RW, Lundelius Jr. EL. 2010. FAUNMAP II: new data for North America with a

554 temporal extension for the Blancan, Irvingtonian and early Rancholabrean, ver. 1.0.

555 Available at: http://www.ucmp.berkeley.edu/faunmap/index.html (accessed 15 March

$556 \quad 2016)$

557 Graham RW, Lundelius Jr. EL, Graham MA, Schroeder EK, Toomey III RS, Anderson E,

558 Barnosky AD, Burns JA, Churcher CS, Grayson DK, Guthrie RD, Harington CR, Jefferson

559 GT, Martin LD, McDonald HG, Morlan RE, Semken Jr. HA, Webb SD, Werdelin L,

560 Wilson MC. 1996. Spatial response of mammals to late Quaternary environmental

$561 \quad$ fluctuations. Science 272:1601-1606.

562 Guernier V, Hochberg ME, Guégan FJ. 2004. Ecology drives the worldwide distribution of

$563 \quad$ human diseases. PLoS Biology 2:e141.

564 Hairston NG, Ellner SP, Geber MA, Yoshida T, Fox JA. 2005. Rapid evolution and the

565 convergence of ecological and evolutionary time. Ecology Letters 8:1114-1127.

566 Hansen MC, DeFries RS, Townshend JR, Sohlberg R, Dimiceli C, Carroll M. 2002. Towards an

567 operational MODIS continuous field of percent tree cover algorithm: examples using

568 AVHRR and MODIS data. Remote Sensing of Environment 83:303-319.

569 Harland SC. 1960. Effect of temperature on growth in weight and tail-length of inbred and

$570 \quad$ hybrid mice. Nature 186:446. 
571 Harrigan RJ, Thomassen HA, Buermann W, Smith TB. 2014. A continental risk assessment of 572 West Nile virus under climate change. Global Change Biology 20:2417-2425.

573 Hijmans RJ, Cameron SE, Parra JL, Jones PG, Jarvis A. 2005. Very high resolution interpolated 574 climate surfaces for global land areas. International Journal of Climatology 25:1965-1978.

575 Hsu M, Harder JD, Lustick SI. 1988. Seasonal energetics of opossums (Didelphis virginiana) in 576 Ohio. Comparative Biochemistry and Physiology A 90:441-443.

577 Iljin NA, Iljin VN. 1930. Temperature effects on the colour of the Siamese cat. Journal of $578 \quad$ Heredity 21:309-318.

579 Jansa SA, Barker FK, Voss RS. 2014. The early diversification history of didelphid marsupials: a $580 \quad$ window into South America's "Splendid Isolation”. Evolution 68:684-695.

581 Kamilar JM, Bradley BJ. 2011. Interspecific variation in primate coat colour supports Gloger's 582 rule. Journal of Biogeography 38:2270-2277.

583 Kamilar JM, Muldoon KM, Lehman SM, Herrera JP. 2012. Testing Bergmann's rule and the 584 resource seasonality hypothesis in Malagasy primates using GIS-based climate data. American Journal of Physical Anthropology 147:401-408.

586 Kanda LL. 2005. Winter energetics of Virginia opossums Didelphis virginiana and implications 587 for the species' northern distributional limit. Ecography 28:731-744.

588 Kanda LL, Fuller TK. 2004. Demographic responses of Virginia opossums to limitation at their 589 northern boundary. Canadian Journal of Zoology 82:1126-1134.

590 Koch PL. 1986. Clinal geographic variation in mammals: implications for the study of $591 \quad$ chronoclines. Paleobiology 12:269-281.

592 Lafferty KD. 2009. The ecology of climate change and infectious diseases. Ecology 90:888-900. 
593 Lee MM, Chu PC, Chan HC. 1969. Magnitude and pattern of compensatory growth in rats after $594 \quad$ cold exposure. Development 21:407-416.

595 Liaw A, Wiener M. 2002. Classification and Regression by randomForest. $R$ news 2:18-22.

596 Lindenmayer DB, Viggers KL, Cunningham RB, Donnelly CF. 1995. Morphological variation 597 among populations of the mountain brushtail possum, Trichosurus caninus Ogilby 598 (Phalangeridae: Marsupialia). Australian Journal of Zoology 43:449-458.

599 Lindsay SL. 1987. Geographic size and non-size variation in Rocky mountain Tamiasciurus 600 hudsonicus: significance in relation to Allen's rule and vicariant biogeography. Journal of $601 \quad$ Mammalogy 68:39-48.

602 Lindstedt SL, Boyce MS. 1985. Seasonality, fasting endurance, and body size in mammals. $603 \quad$ American Naturalist 125:873-878.

604 Lomolino MV, Perault DR. 2007. Body size variation of mammals in a fragmented, temperate 605 rainforest. Conservation Biology 21:1059-1069.

606 Long DG, Drinkwater MR, Holt B, Saatchi S, Bertoia C. 2001. Global ice and land climate 607 studies using scatterometer image data. Eos Transactions American Geophysical Union $608 \quad \mathbf{8 2 : 5 0 3 .}$

609 Lustick S, Lustick DD. 1972. Energetics in the opossum, Didelphis marsupialis virginiana. $610 \quad$ Comparative Biochemistry and Physiology A 43:643-647.

611 Mackintosh JA. 2001. The antimicrobial properties of melanocytes, melanosomes and melanin 612 and the evolution of black skin. Journal of Theoretical Biology 21:101-113.

613 Männiste M, Hõrak P. 2014. Emerging infectious disease selects for darker plumage coloration 614 in greenfinches. Frontiers in Ecology and Evolution 2:4. 
615 Martin JGA, Festa-Bianchet M, Côté SD, Blumstein DT. 2013. Detecting between-individual 616 differences in hind-foot length in populations of wild mammals. Canadian Journal of 617 Zoology 91:118-123.

618 Mascaro J, Asner GP, Knapp DE, Kennedy-Bowdoin T, Martin RE, Anderson C, Higgins M, 619 Chadwick KD. 2014. A tale of two "forests": random forest machine learning aids tropical 620 forest carbon mapping. PloS ONE 9:e85993.

621 Mayr E. 1956. Geographical character gradients and climatic adaptation. Evolution 10:105-108.

622 McManus JJ. 1969. Temperature regulation in the opossum, Didelphis virginiana marsupialis. 623 Journal of Mammalogy 50:550-558.

624 McNab BK. 1978. The comparative energetics of Neotropical marsupials. Journal of 625 Comparative Physiology B 125:115-128.

626 Meiri S, Dayan T. 2003. On the validity of Bergmann's rule. Journal of Biogeography 30:331$627 \quad 351$.

628 Millar JS, Hickling GJ. 1990. Fasting endurance and the evolution of mammalian body size. $629 \quad$ Functional Ecology 4:5-12.

630 Millien V, Lyons S, Olson L, Smith FA, Wilson AB, Yom-Tov Y. 2006. Ecotypic variation in 631 the context of global climate change: revisiting the rules. Ecology Letters 9:853-869.

632 Morgan GS. 2008. Vertebrate fauna and geochronology of the great american biotic interchange 633 in North America. In: Lucas SG, Morgan GS, Spielmann JA, Prothero DR, eds. Neogene 634 Mammals. Albuquerque: New Mexico Museum of Natural History and Science Bulletin $63544,93-140$

636 Niles DM. 1973. Adaptive variation in body size and skeletal proportions of horned larks in the 637 southwestern United States. Evolution 27:405-426. 
638 Paradis E, Claude J, Strimmer K. 2004. APE: analyses of phylogenetics and evolution in R 639 language. Bioinformatics 20:289-290

640 Pfennig DW, Wund MA, Snell-Rood EC, Cruickshank T, Schlichting CD, Moczek AP. 2010.

641 Phenotypic plasticity's impacts on diversification and speciation. Trends in Ecology and $642 \quad$ Evolution 25:459-467.

643 Post PW, Daniels F, Binford RT. 1975. Cold injury and the evolution of "white" skin. - Human 644 Biology 47:65-80.

645 Prasad AM, Iverson LR, Liaw A. 2006. Newer classification and regression tree techniques:

646 bagging and random forests for ecological prediction. Ecosystems 9:181-199.

647 Quin DG, Smith AP, Norton TW. 1996. Eco-geographic variation in size and sexual dimorphism

648 in sugar gliders and squirrel gliders (Marsupialia:Petauridae). Australian Journal of $649 \quad$ Zoology 44:19-45.

650 R Core Team. 2015. R: a language and environment for statistical computing. Vienna: $\mathrm{R}$

651 Foundation for Statistical Computing. Available at: http://www.R-project.org/ (accessed 6

652 December 2015)

653 Rensch B. 1938. Some problems of geographical variation and species-formation. Proceedings 654 of the Linnean Society of London 150:275-285.

655 Riek A, Geiser F. 2012. Developmental phenotypic plasticity in a marsupial mammal. Journal of 656 Experimental Biology 215:1552-1558.

657 Robinson R. 1973. Acromelanic albinism in mammals. Genetica 44:454-458.

658 Rosenzweig ML. 1968. Net primary productivity of terrestrial communities: prediction from 659 climatological data. American Naturalist 102:67-74. 
660 Serrat MA. 2013. Allen's rule revisited: temperature influences bone elongation during a critical 661 period of postnatal development. The Anatomical Record 296:1534-1545.

662 Stern C. 1968. Genetic Mosaics and Other Essays. Cambridge: Harvard University Press.

663 Strobl C, Malley J, Tutz G. 2009. An introduction to recursive partitioning: rationale, 664 application, and characteristics of classification and regression trees, bagging, and random 665 forests. Psychological Methods 14:323-348.

666 Suttie JM, Mitchell B. 1983. Jaw length and hind foot length as measures of skeletal 667 development of Red deer (Cervus elaphus). Journal of Zoology 200:431-434.

668 Symonds MR, Tattersall GJ. 2010. Geographical variation in bill size across bird species 669 provides evidence for Allen's rule. The American Naturalist 176:188-197.

670 Terada C, Tatsuzawa S, Takashi S. 2012. Ecological correlates and determinants of deer 671 morphology. Oecologia 169:981-994.

672 Tattersall GJ, Sinclair BJ, Withers PC, Fields PA, Seebacher F, Cooper CE, Maloney SK. 2012.

673 Coping with thermal challenges: physiological adaptations to environmental temperatures. 674 Comprehensive Physiology 2:2151-2202.

675 Tucker CJ, Sellers PJ. 1986. Satellite remote sensing of primary production. International $676 \quad$ Journal of Remote Sensing 7:1395-1416.

677 Tyndale-Biscoe H. 2005. Life of marsupials. Collingwood: CSIRO Publishing.

678 Weaver ME, Ingram DL. 1969. Morphological changes in swine associated with environmental 679 temperature. Ecology 50:710-713.

680 Weber JM, O'Connor T. 2000. Energy metabolism of the Virginia opossum during fasting and $681 \quad$ exercise. Journal of Experimental Biology 203:1365-1371.

682 Wickham H. 2009. ggplot2: Elegant Graphics for Data Analysis. New York: Springer-Verlag. 
683 Wigginton JD, Dobson FS. 1999. Environmental influences on geographic variation in body size 684 of western bobcats. Canadian Journal of Zoology 77:802-813.

685 Yom-Tov Y, Nix H. 1986. Climatological correlates for body size of five species of Australian 686 mammals. Biological Journal of the Linnean Society 29:245-262.

687 
Figure 1

Geographic range of Didelphis virginiana and collecting localities.

The shaded light purple area represents the reported distribution range for the species (Cuarón et al. 2008) and the collecting localities for the museum specimens analyzed in this study are marked by black dots.

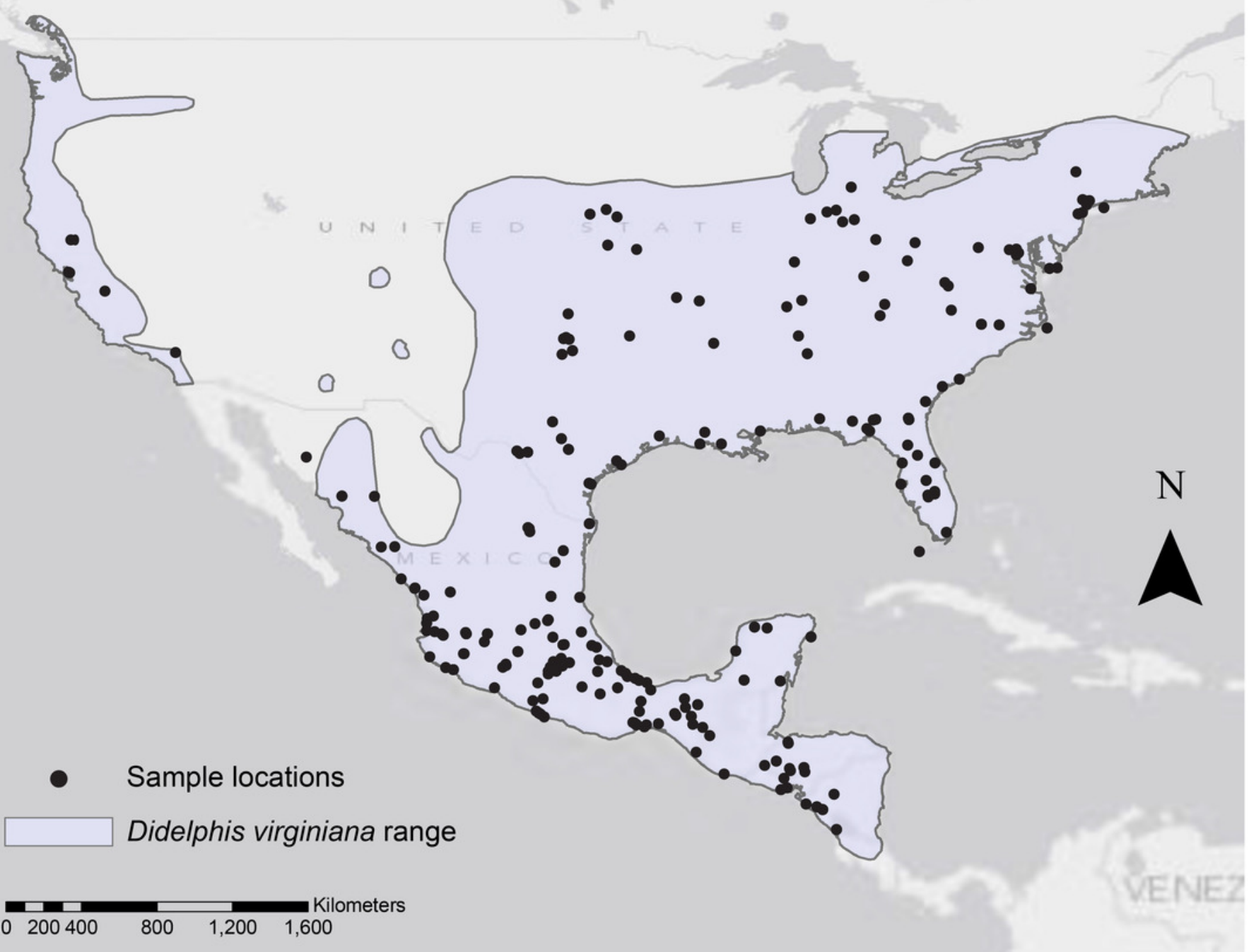




\section{Figure 2}

Phenotypic variation in Didelphis virginiana.

Phenotypic differences between specimens from southern and northern populations. (A) Differences in body size (i.e. head and body) and coat coloration of the face and dorsal part of the torso. (B) Variation in tail length, proportion of tail pigmentation, and ventral and dorsal hindfoot toes pigmentation. (C) Dissimilarities in the proportion of ear pigmentation. 


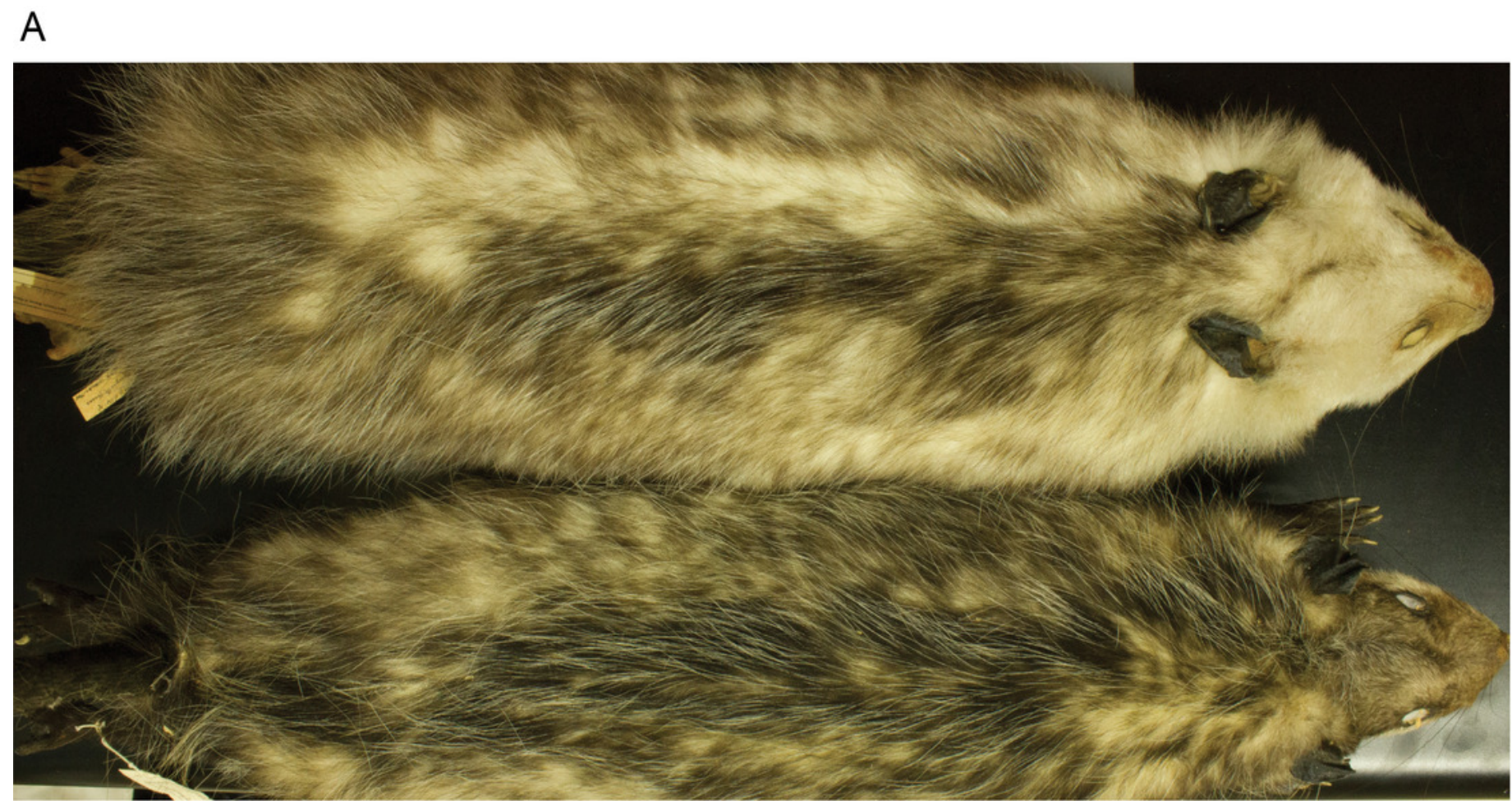

B

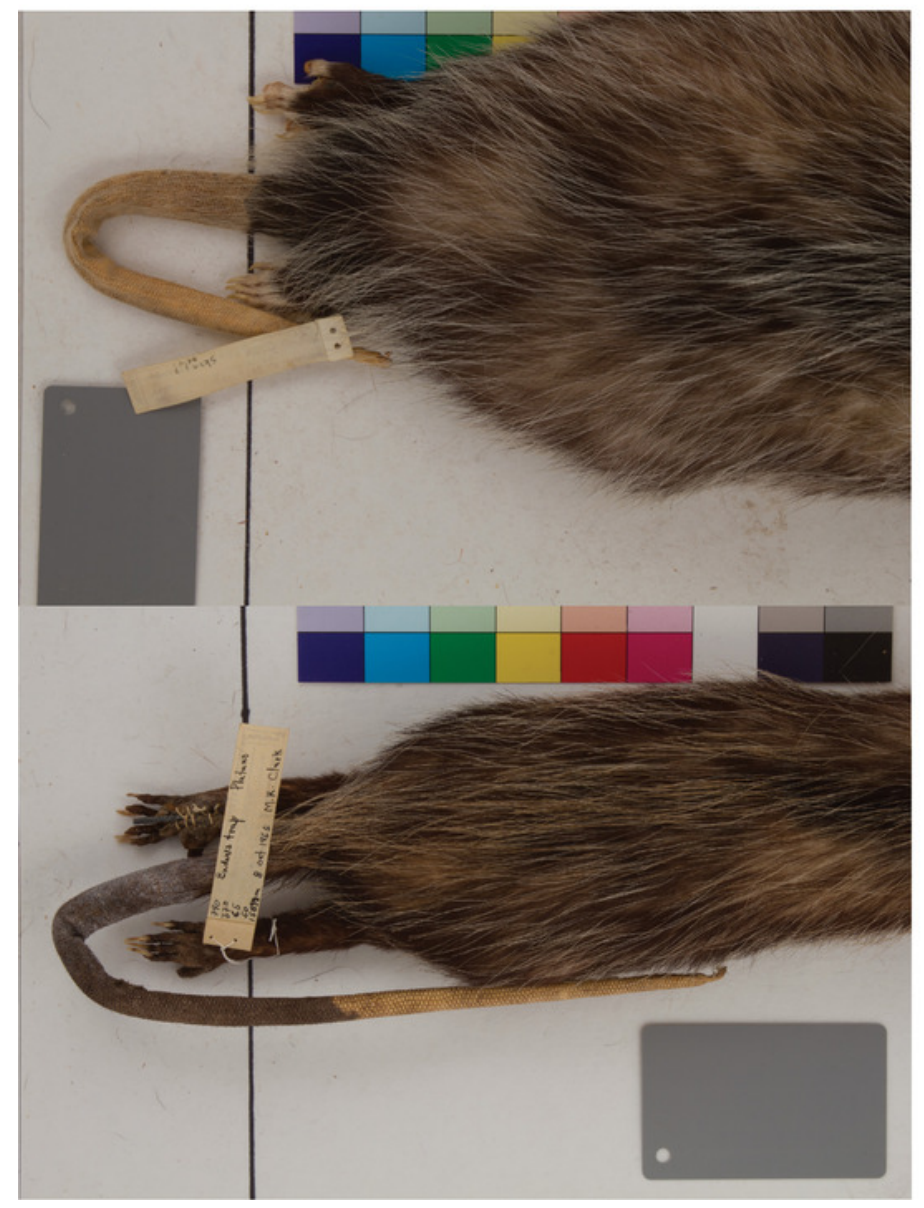

C

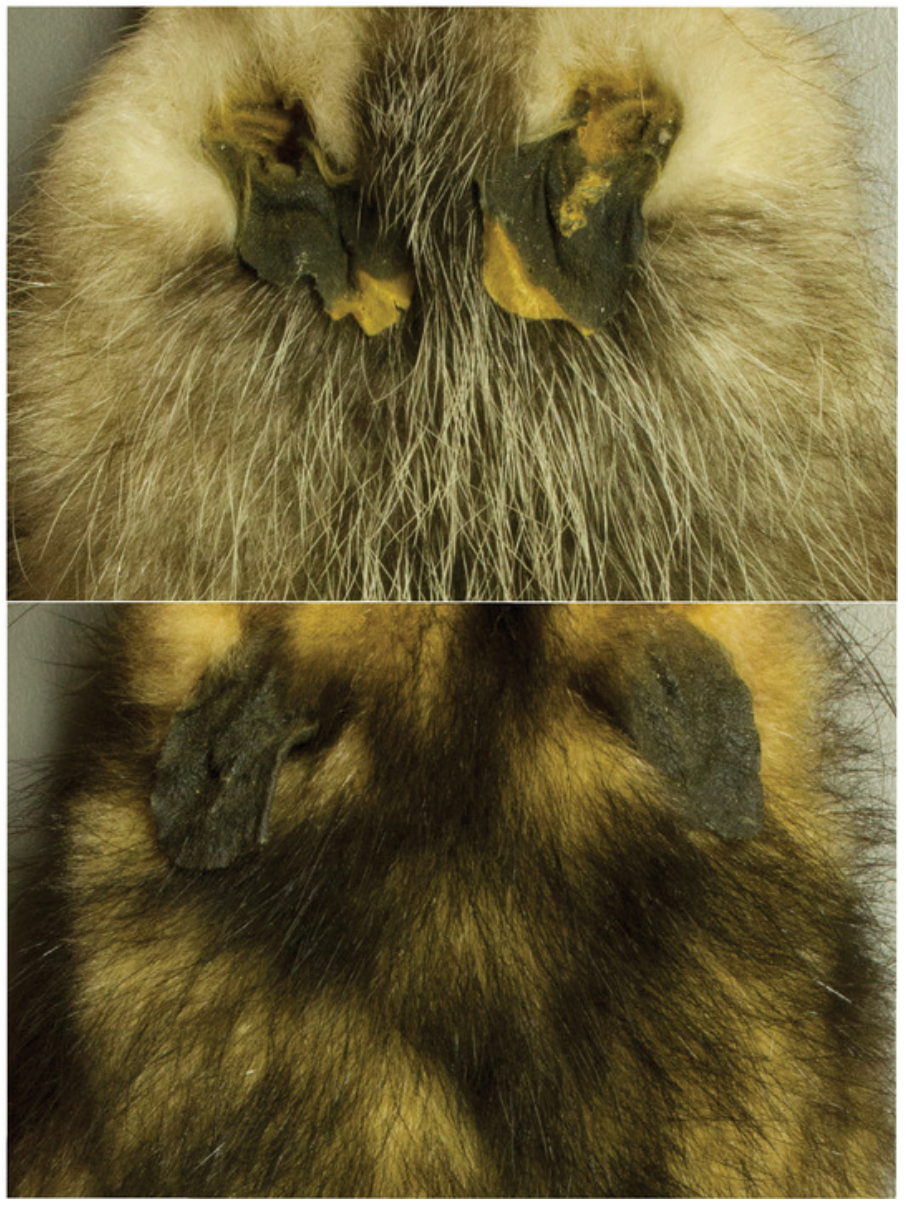




\section{Figure 3}

Sites on Didelphis virginiana museum skin from which reflectance measurements were taken.

Nine sites were measured on the torso (three on each flank and three on the dorsal stripe) and three sites on the face (i.e. rostrum, cheek and temporal regions).

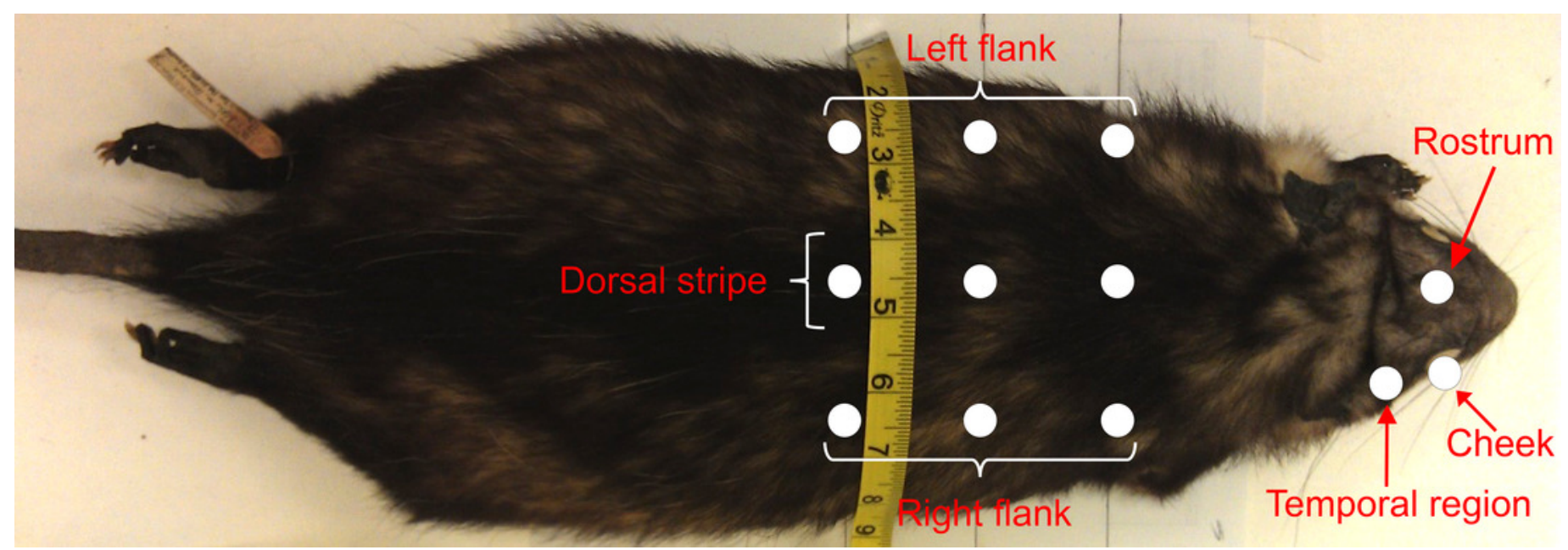


Figure 4 (on next page)

Scatter plots of the relationship between phenotypic traits and latitude.

The non-linear loess function line is shown, indicating the trend of the relationship. (A) body length, (B) hindfoot length, (C) tail length, (D) ear length, (E) proportion of tail pigmentation, $(F)$ proportion of ear pigmentation, $(G)$ proportion of toe ventral pigmentation, $(\mathrm{H})$ proportion of toe dorsal pigmentation, (I) rostrum lightness, (J) temporal region lightness, (K) cheek lightness, (L) torso lightness. For cheek and torso lightness, the grey triangles and line represent the data for males while the black circles and line represent the data for females. 


\section{Figure 5 (on next page)}

Importance scores for each predictor variable (including geographic variables) used as input to random forest combined models for all phenotypic traits.

Variables with higher mean square error (calculated as the average increase in squared residuals when the variable is permuted) are more important. Variables shown with a black circle are those that remained important as the model was refined. (A) body length, $(B)$ hindfoot length, $(C)$ tail length, $(D)$ ear length, $(E)$ proportion of tail pigmentation, $(F)$ proportion of ear pigmentation, $(\mathrm{G})$ proportion of toe ventral pigmentation, $(\mathrm{H})$ proportion of toe dorsal pigmentation, (I) rostrum lightness, $(\mathrm{J})$ temporal region lightness, $(\mathrm{K})$ cheek lightness in females, (L) cheek lightness in males, (M) torso lightness in females, (N) torso lightness in males. Bio1 $=$ Annual mean temperature, Bio2 $=$ Mean diurnal range, $\mathrm{Bio} 4=$ Temperature seasonality, Bio10 $=$ Mean temperature warmest quarter, Biol1 $=$ Mean temperature of coldest quarter, Bio12 $=$ Annual precipitation, Bio15 $=$ Precipitation seasonality, Bio19 $=$ Precipitation of coldest quarter, NDVIMAX $=$ Normalized difference vegetation index maximum value, TREECOV $=$ Percent tree cover, ELEV = elevation, ROUGH $=$ Surface moisture, LAT $=$ Latitude, LONG $=$ Longitude. 


\section{Figure 6}

Maps of geographic variation for the most important environmental predictors associated with trait variation in Didelphis virginiana.

(A) Temperature seasonality, (B) temperature of the coldest month, (C) precipitation seasonality and (D) precipitation of the coldest quarter. The white dots show the distribution of Virginia opossum specimens used in this study.
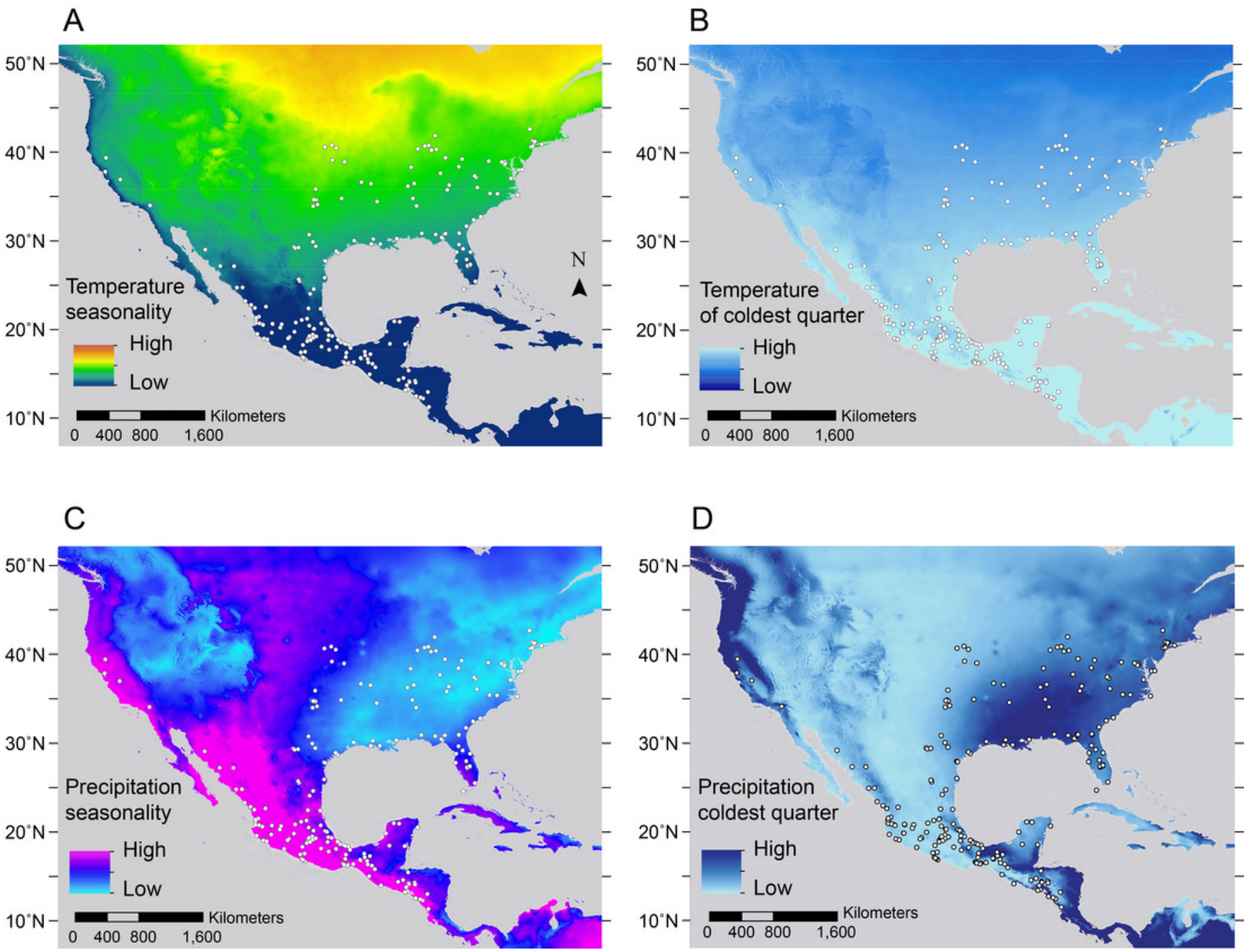


\section{Table $\mathbf{1}$ (on next page)}

Pearson and Spearman correlation between Didelphis virginiana phenotypic traits and latitude. 


\begin{tabular}{llll}
\hline Trait & Sample size & $\begin{array}{l}\text { Pearson } \\
\text { correlation }\end{array}$ & $\begin{array}{l}\text { Spearman } \\
\text { correlation }\end{array}$ \\
\hline Body length & 348 & $0.314^{* * * *}$ & n.a. \\
Hindfoot length & 345 & $0.284^{* * *}$ & n.a. \\
Tail length & 348 & $-0.613^{* * *}$ & n.a. \\
Ear length & 185 & $-0.172^{*}$ & n.a. \\
Tail pigmentation & 340 & n.a. & $-0.701^{* * * *}$ \\
Ear pigmentation & 293 & n.a. & $-0.559^{* * * *}$ \\
Toe ventral pigmentation & 334 & n.a. & $-0.583^{* * * *}$ \\
Toe dorsal pigmentation & 338 & n.a. & $-0.548^{* * * *}$ \\
Rostrum lightness & 345 & n.a. & $0.679^{* * * *}$ \\
Temporal region lightness & 345 & n.a. & $0.719^{* * * *}$ \\
Cheek lightness & & & \\
F & 159 & $0.517^{* * * *}$ & n.a. \\
M & 186 & $0.512^{* * * *}$ & n.a. \\
Torso lightness & & & n.a. \\
F & 159 & $0.298^{* * *}$ & n.a. \\
M & 186 & $0.251^{* * *}$ & \\
\hline
\end{tabular}

F: Females; M: Males.

n.a: Not applicable.

${ }^{*} P<0.05 ;{ }^{* *} P<0.01 ;{ }^{* * *} P<0.001 ;{ }^{* * * *} P<0.0001$. 


\section{Table 2 (on next page)}

Random forest models for each phenotypic trait and the percentage of phenotypic variance they explain.

For most traits, the combined models that include environmental and geographic variables together explain more of the phenotypic variation than the environmental only and geographic only models. When LONG is in cursive it means that it was not among the top variables of that particular model (Fig. 5), but was included to take into account spatial autocorrelation. The most important variable of the models is on the left, diminishing in importance towards the right. 
Traits
Best models including environmental and geographic variables.

\section{$\%$ of}

phenotypic

variation

explained by

the models

including

environment

al and

geographic

variables.
$\%$ of

phenotypic

variation

explained by

environmental variables only

LAT,

LAT, LONG)

$\%$ of

phenotypic

variation

explained by geographic

variables only (i.e. (ONG)

\section{Body Dimensions}

Body length

LAT, Bio4, Bio11, Bio2, LONG

$14.95 \%$

$11.82 \%$

$9.96 \%$

Hindfoot length

Bio11, LONG, LAT, Bio4

$12.75 \%$

$3.39 \%$

$10.77 \%$

Tail length

LAT, LONG, Bio4, Bio1, Bio11

$47.42 \%$

$36.91 \%$

$50.05 \%$

Ear length

Bio1, LAT, Bio4, ROUGH, LONG

$13.11 \%$

$11.51 \%$

$-1.73 \%$

Skin Pigmentation

Tail pigmentation

LONG, LAT, Bio4, Bio11, Bio15

$62.56 \%$

$60.0 \%$

$61.14 \%$

Ear pigmentation

LONG, Bio15, Bio4, LAT

$62.18 \%$

$49.07 \%$

$60.78 \%$

Toe ventral

LAT, Bio 19, LONG, Bio4, Bio11 59.86\%

$57.57 \%$

$58.9 \%$

pigmentation

Toe dorsal

LAT, Bio11, Bio15, Bio1, LONG

$31.17 \%$

$27.38 \%$

$34.5 \%$

pigmentation

Face coloration

Rostrum lightness

LAT, Bio4, LONG, Bio11, Bio19 76.04\%

$73.64 \%$

$74.82 \%$

Temporal lightness

LONG, LAT, Bio4, Bio11, Bio15 78.34\%

$72.29 \%$

$79.04 \%$

Cheek lightness

F M
LAT, Bio4, Bio11, Bio19, LONG

LAT, Bio11, Bio4, Bio15, LONG
$13.75 \%$

$29.75 \%$
$5.74 \%$

$27.65 \%$
$16.87 \%$

$24.06 \%$ 
Torso lightness

F M
Bio4, Bio12, LAT, Bio11, LONG

Bio4, Bio11, LAT, Bio12, LONG
$19.88 \%$

$14.41 \%$
$18.45 \%$

$15.78 \%$
$14.76 \%$

$0.25 \%$

F: Females; M: Males.

Bio1: Annual mean temperature

Bio2: Mean diurnal range

Bio4: Temperature seasonality

Bio11: Mean temperature of coldest quarter

Bio12: Annual precipitation

Bio15: Precipitation seasonality

Bio19: Precipitation of coldest quarter

ROUGH: Surface moisture

LAT: Latitude

LONG: Longitude 